\title{
REPERTORIUM VAN TIJDSCHRIFT-LITE- RATUUR OP HET GEBIED VAN ACCOUN . TANCY EN BEDRIJFSHUISHOUDKUNDE
}

\author{
Redactie: $\quad$ L. A. Bakker \\ Drs. G. L. Groeneveld \\ Drs. H. Haverkamp \\ en Drs. P. F. R. Stol
}

\section{A. ACCOUNTANCY}

\section{HET ACCOUNTANTSBEROEP}

\section{Vijf en twintig jaat rijksaccountantsdienst}

Dijker, R. A. - Bij het zilveren jubileum van den Rijksaccountantsdienst biedt Schr., na herdenking van enkele feiten, de gelukwenschen van de redactie aan.

Blaey, W. N. de - Schr. memoreert de ontwikkeling van dezen dienst en geeft enkele desiderata.

A II 2

De Naamlooze Vennootschap April 1941

\section{LEER VAN DE INRICHTING}

\section{De voorsteekinrichting}

Poelvoorde. H. L. van - Aanduiding van nut en mogelijkheden van de voorsteek-inrichting op schrijfmachines.

A III 3

De Zakenwereld 21 Juni 1941

\section{Administratieve en mechanische hulpmiddelen}

Beschrijving van de Pelikaan rotafix stencilmachines, de Goerz schrijvende telmachine met een telwerk en van het linea recta hangmappensysteem, dat speciaal geschikt is voor het opbergen van oud archief.

Komt toepassing van de vervangingswaardeleer in de boekhouding niet voor?

Rietschoten, A. M. va n - Schr. houdt een warm pleidooi voor de mogelijkheden om de vervangingswaarde in de boekhouding toe te passen, ondanks het feit. dat dit in vele gevallen met moeilijkheden gepaard zal gaan. Een cijfervoorbeeld licht toe hoe de winsten en verliezen, welke voortvloeien uit het aanhouden van een speculatievoorraad te scheiden zijn van de normale bedrijfsresultaten.

A III 3 Maandblad voor Accountancy en Bedrijfshuishoudkunde Sept. 1940

\section{Interne organisatie van een Hollerithkamer}

$\mathrm{H}$ (ijner), Ir. C. - De organisatie van een Hollerith-afdeeling wijkt in principe niet af van de organisatie van andere afdeelingen, waar met kostbare en gevoelige machines werkzaamheden van uiteenloopenden aard moeten worden verricht. Schr. meent daarom dat het probleem een sterk technisch accent heeft. De in dit artikel te behandelen stof wordt verdeeld in a, vastleggen van de werkwijze, b. prestatiecontrôle. c. werkregeling, d. functieverdeeling. Schr. geeft eenige voorbeelden van te gebruiken formulieren.

A III 3

Bedrijfsorganisatic Maart 1941

\section{Dubbele voorraadadministratie}

St arreveld, R. W. - De wenschelijkheid om een voorraadadministratie zoowel in het magazijn als op kantoor bij te houden kan bij velen geen weerklank vinden, omdat zij het tweemaal administreeren als inefficient beschouwen.

De schrijver van dit artikel toont evenwel aan de hand van een voorbeeld uit de practijk aan, dat het zeer goed mogelijk is, de vermeende inefficiencies te vermijden en nochtans alle voordeelen, verbonden aan een dubbele administratie, te realiseeren.

A III 3

Organisatic en Efficiency Juni 1941 


\section{B. BEDRIJFSHUISHOUDKUNDE}

\section{a. ALGEMEENE BEDRIJFSHUISHOLIDKUNDE}

\section{WAARNEMINGSMIDDELEN}

\section{Econometrie}

Keesing. dr. F. A. G. - De mathematische analyse is in staat tot verdieping van economisch inzicht bij te dragen. Als middel on de niet-mathematisch geformuleerde theorie te verifieeren is zij steeds van belang. Doch de econometrie bezit inhaerente zwakheden, die haar juiste toepassing dikwijls uitermate bezwaarlijk maken. Bezwaarlijk is ook, dat de economie van talrijke gegevens uitgaat en de mogelijkheid tot verrvoortgezette reductie in het algemeen ontbreekt. De resultaten der econometrie zullen niet steeds evenredig zijn aan de inspanning. die aan haar beoefening ten koste wordt gelegd.

B a III 2

De Economist Februari 1941

\section{Beheersdocumentatie}

Extra-nummer, gewijd aan beheersdocumentatie, waaronder de inleider, Ir. F. Donker Duyvis. verstaat het verzamelen, ordenen en distribueeren van gegevens, die voor een bepaalde administratie van belang zijn met het doel op een gegeven oogenblik omtrent een gegeven onderwerp op doelmatige wijze te beschikken over kennis en - waar mogelijk - over de authentieke documenten waarin die kennis is vervat.

Eenige toepassingen worden beschreven door J. Th. Kummer, G. de Wit en $H$. van der Laan. A. de Jong schrijft over mechanische hulpmiddelen voor het verwerken van binnenkomende en uitgaande post, dr. T. Kuiper en A. Steenhuizen over het personeel van het archief, ir. A. Teyrich over normalisatie van formulieren, terwijl het N.I.D.E.R. cen lijst van Nederlandsche publicaties over Documentatie toevoegt.

B a III 2 Mededeclingen van het Nederlandsch Institunt voor Efficiency, enz. Mei 1941

\section{Doel en werkterrein van de bedrijfseconomische statistiek}

Stridiron, dr. J. G. - Schr. bespreekt het wezen van de statistiek, haar taak. de aard van het statistisch oordeel, het karakter van de bedrijfseconomische statistiek. de verhouding tusschen statistiek en administratie. de plaats van de bedrijfseconomische statistiek in het administratief geheel naar de Duitsche literatutır en de onderscheiding tusschen interne- en externe statistiek. De bedrijfsvergelijking is een belangrijke tak van de statistische analyse in het bedrijf. hetgeen schr. met enkele voorbeelden demonstreert.

B a III 2

De Economist Juni 1941

\section{De geconsolideerde jaarrekening}

L oos, J. - Schr, zet in deze artikelen de voordeelen, verbonden aan de geconsolideerde jaarrekening, duidelijk uiteen. Cijfervoorbeelden lichten de wijze, waarop de cijfers worden gecombineerd, toe.

B a III 3 Maandblad voor Accountancy en Bedrïfshuishoudkunde Sept.. Oct. en Nov. 1940

\section{LEER VAN DEN KOSTPRIJS EN DE PRIJSVORMING}

\section{Vraagstukken der uniforme kostprijsberekening voor gieterijen}

Bez emer. Ir. T. J. - Reeds vroeger zijn vruchteloos pogingen in het werk gesteld om te komen tot een algemeen aanvaard systeem van kostprijsberekening in dezen bedrijfstak. Thans is hier te meer aanleiding voor. Schr. maakt bij zijn behandeling een indeeling naar de verschillende doelstellingen, welke met de uniforme calculatie kunnen worden beoogd. In de eerste plats is daar de uniforme kostensplitsing in den zin van een uniforme categorische kostensplitsing. Deze kan van belang zijn voor het nagaan van den invloed van prijsstijgingen. Voor een doeltreffende bedrijfsvergelijking is het vorige, gezien het uiteenloopende karakter van de gieterij-bedrijven, niet voldoende. maar moet ook het calculatie-schema uniform zijn. Dit behoeft nog niet te leiden tot volkomen gelijke administratie, maar beoogd wordt het geven van richtlijnen, die de betrouwbaarheid van de kostprijsberekening waarborgen.

$B$ a IV 2 a

De Gietcrij Mei 1941

\section{Komt toepassing van de vervangingswaardeleer in de boekhouding niet voor?}

Rietschoten. A. M. van - Schr. houdt een warm pleidooi voor de mogelijkheden om de vervangingswaarde in de boekhouding toe te passen, ondanks het feit, 
dat dit in vele gevallen met moeilijkheden gepaard zal gaan. Een cijfervoorbeeld licht toe hoe de winsten en verliezen, welke voortvloeien uit het aanhouden van een speculatievoorraad te scheiden zijn van de normale bedrijfsresultaten.

B a IV 2b Maandblad voor Accountancy en Bedrijfshuishoudkunde September 1940

De rentekosten in het kader der theorie van de vervangingswaarde

$\mathrm{Schroeff}$, Dr. H, J. van der - Schr. behandelt het probleem van de rentekosten en geeft een toelichting op de verschillende opvattingen in de litteratuur aangaande dit probleem.

$\mathrm{B}$ a IV 3 Maandblad voor Accountancy en Bedrijfshuishoudkunde Juli 1940

\section{LEER VAN DE FINANCIERING}

\section{Beursnoteering voor vrijwillig volgestorte aandeelen; een novum}

$\mathrm{M}$ a a s dij k, H. C. va n - Indien enkele bezwaren zijn ondervangen dan staat aan uitbreiding van bovengenoemd instituut niets in den weg en is een aantrekkelijk nieuw beleggingsobject geschapen.

$\mathrm{B}$ a V $3 \mathrm{a}$

Economische Statistische Berichten 18 Juni 1941

\section{LEER VAN DE ORGANISATIE}

\section{Autonomie en staatsinmenging in beroep en bedrijf in Duitschland}

Holle nberg. dr. A. - Schr. bespreekt 1. De bedrijfsgemeenschappen en het Duitsche Arbeidsfront, 2. De bedrijfsorganisatie voor Handel, Nijverheid en Verkeer. 3. De organisatie van het Ambacht.

B a VI 3

De Economist Maart en April 1941

De verbruikscoöperatie in de corporatieve orde

Charbo, J. J. A. - De verbruikscoöperatie heeft ook in de corporatief geordende maatschappij recht op bestaan, omdat $z i j$ nuttig werk verricht, een plaats veroverd heeft, velen een bestaan geeft, omdat $z$ ij de maatschappelijke. differentiatie bevordert en omdat zij in de corporatieve orde op bijzonder goede wijze de belangen van onderneming en verbruiker zal kunnen coördineeren.

$\mathrm{B}$ a VI 10

Economie April 1941

\section{Reclame in dezen tijd}

Gelink, A. E. - Bij vele ondernemers bestaat sinds het uitbreken van den oorlog de neiging de uitgaven voor reclame te beperken. Schr. wijst op de gevaren die hieraan voor het bedrijf verbonden zijn en geeft eenige aanwijzingen voor de wijze waarop de reclame onder de huidige omstandigheden moet worden gevoerd.

B a VI 11 Theorie en Techniek van het Middenstandsbedrijf Mei 1941

De functie van den personeels-chef en de organisatie van de afdeeling „Personeel”

Scheurs, dr. Th. A. M. - Schr. geeft aan, wat er ontbreekt in de bedrijven die het zonder personeels-afdeeling doen en laat zien, hoe de technische, paedagogische, sociale en cultureele ontwikkeling van het personeel de volle aandacht der personeelsinstantie verdienen.

B a VI 16 Mededeelingen van het Nederlandsch Instituut voor Efficiency, enz. Juni 1941

\section{De adviseur en het bedrijf}

Kui per, dr. T. - Het is frappant, op hoeveel gebieden het verschijnsel van de gelijkvormigheid zich openbaart. Dit blijkt o.m. uit onafhankelijk verrichtte studies naar de voorkeur voor bepaalde cijfers.

Ook het gemak, waarmede de adviseur zich in een bepaald bedrijf oriënteert, is onder meer aan dit verschijnsel van de gelijkvormigheid toe te schrijven. De problemen. waarvoor hij zich in zeer verschillend geaarde bedrijven geplaatst ziet, toonen n.l. dikwijls een markante gelijkenis.

$\mathrm{B}$ a VI 17

Organisatie en Efficiency Juni 1941

\section{De fabricagekosten bij het in combinatic bedienen van machines of machine-eenheden}

$Z$ oe thout, Ir. D. - Schr. behandelt het probleem, hoeveel machines men een arbeider het meest rationeel kan laten bedienen. Het eene uiterste is voor iedere machine een arbeider aan te stellen, waardoor leegloop van de machines beslist voorkomen 
wordt. Het andere uiterste is zooveel machines door een arbeider te laten bedienen dat hij zeker geen moment zonder werk is. Daar tusschen ligt een compromis, waarbij de totale kosten per producteenheid zoo laag mogelijk zijn. Bij dit vraagstuk moet er rekening mede gehouden worden dat er onderbrekingen van verschillenden aard zijn, regelmatige, zooals het verwisselen van spoelen en onregelmatige, zooals draadbreuk. Schr. ontwikkelt de methoden, die gevolgd moeten worden ter berekening van het meest economische aantal te bedienen machines en geeft een aantal karakteristieke en uiteenloopende voorbeelden waarin deze methoden worden toegepast.

B a VI 19

De Ingenieur 11 April 1941

\section{Honoreering van reizigers}

V. e rvooren, L. C. - In dit en een aansluitend artikel worden de verschillende honoreerings-methoden beschouwd. Globaal vallen een negental groepen te onderscheiden, meerendeels met diverse varianten, waarvan de groepen met vast salaris en/of commissie nu in de eerste plaats worden besproken.

B a VI 21

Organisatie en Efficiency Juni 1941

\section{Efficiency van het reizigersapparaat}

As. H. va n - Aangezien de bedrijfsresultaten direct afhankelijk zijn van de grootte van den verkoop, is het noodzakelijk, die maatregelen te nemen, welke de efficiency van het reizigersapparaat kunnen opvoeren.

De te nemen maatregelen worden opgesomd, waarna een viertal punten aan een meer uitvoerige bespreking worden onderworpen.

B a VI 21

Organisatie en Efficiency Juni 1941

\section{LEER VAN DE ARBEIDSVOORWAARDEN}

\section{Statisch en dynamisch denken in verband met het organiseeren}

Steenhuizen, A. - De dynamische denkwijze is een noodzakelijkheid bij het verrichten van organisatiewerk. De grootte van het dynamische denkvermogen werd bij een aantal proefpersonen met behulp van een schriftelijke opgave vastgesteld.

In dit artikel wordt een statische tnalyse van de resultaten van dit onderzoek aan een beschouwing onderworpen.

B a VII 5

Organisatie en Efficiency Juni 1941

\section{Ervaringen met bazencursussen}

Silva, D. J. da - Evenmin als de techniek staat de organisatie-arbeid stil. De fabrieksbaas behoort dus ook ingelicht te zijn omtrent de beteekenis en draagwijdte van allerlei organisatorische maatregelen, die in zijn afdeeling genomen worden. Welke ervaringen de bazencursussen, die vanwege het Nederlandsch Instituut voor Efficiency tot dit doel worden georganiseerd, opleverden, behandelt dit artikel.

B a VII 7

Organisatie en Efficiency Juni 1941

\section{b. BIJZONDERE BEDRIJVEN}

\section{LANDBOUW - EN CULTUURBEDRIJVEN}

\section{Distributie tijdens twee oorlogen}

Redactie - In dit artikel worden de maatregelen beschreven, die de overheid gedurende den vorigen oorlog genomen heeft teneinde $d$ voedselvoorziening te waarborgen. De regeling welke in 1939 is getroffen wijkt in sterke mate af van het stelsel dat tijdens den vorigen oorlog en vooral in het begin daarvan bestond. Het wordt gekenmerkt door de landelijke uniformiteit, sterke centralisatie, vroegtijdige invoering, oprichting van rijksbureaux voor Handel en Nijverheid en inschakeling van het landbouwcrisisapparaat.

B b IV 1

Economische Voorlichting $30 \mathrm{Mei} 1941$

\section{Palmolie}

Row a a n, Dr. P. A. - De oliepalm, die thans een belangrijke rol speelt in de vetvoorziening van de wereld, kwam voor 1920 vrijwel uitsluitend voor in Afrika. De oliewinning geschiedde daar op tamelijk primitieve wijze. Dit in tegenstelling tot de cultuur, die in de laatste decennia in Ned. Indië opkwam. De aanplantingen vinden we hoofdzakelijk in het cultuurgebied van Sumatra's Oostkust. Ook in Malaya is deze 
cultuur tot bloei gekomen. De Ned. Indische uitvoer is aanzienlijk en vooral gericht naar de Vereenigde Staten. De palmolie vindt de laatste jaren behalve in de zeepindustrie meer en meer toepassing in de spijsverindustrie. Het artikel geeft eenig statistisch materiaal.

$\mathrm{B}$ b IV 10

De vet-, olie- en margarine-industrie 6 Juni 1941

\section{INDUSTRIE}

\section{De positie der belangrijkste grondstoffen voor voeding en textielgoederen in Con- tinentaal-Europa}

Ettinger, ir. J.van en Rombouts A. L. G. M. - De totale positie van de voeding is zoodanig, dat onder voorwaarde van gelijkmatige verdeeling van de beschikbare voedingsmiddelen voor Continentaal-Europa, ernstige tekorten kunnen worden vermeden. De grondstoffenpositie zal wel leiden tot een groot tekort aan textielgoederen van klassieke grondstoffen.

$\mathrm{B}$ b V 1

De Economist Febr. 1941

\section{De energiehuishouding van Continentaal-Europa}

Et tinger, ir. J. van en Rombouts A. L. G. M. - Schrijvers gaan de verhouding na tusschen productie en verbruik van onze energiebronnen. $Z$ ij construeeren tenslotte zelfvoorzienigspercentages der totale energie in verschillende declen van Continentasl-Europa. Hieruit blijkt, dat de totale energieverzorging nagenoeg verzekerd is. Noord- en Zuid-Europa hebben tekorten, ondanks de benutting van waterkracht. terwijl ook West-Europa voor een groot deel van aanvoer uit andere gebieden afhankelijk is. Het energievraagstuk is er dus een van verbruiksbeperking, van transport en van productie van synthetische vloeistoffen.

$\mathrm{B} b \mathrm{~V} 1$

De Economist Mei 1941

\section{Het vormgeven aan het industrie-product}

$\mathrm{Kalff}$, Ir. L. - Met de gewoonte om voor het industrieproduct de oude handwerksvormen na te bootsen, heeft men in da laatste decennia gebroken. Er is naar gestreefd een nieuwe schoonheid te vinden. Schr. meent dat men hierin slechts ten deele geslaagd is. Aan de hand van enkele voorbeelden toont schr. aan met welk een veelheid van eischen de ontwerpen rekening hebben te houden en hoe de fabrikanten er bij vele artikelen naar streven van jaar tot jaar verscheidenheid in hun series te brengen.

B b V 1

Economisch Technisch Tijdschrift Mri 1941

\section{Hoogovens en Staalfabrieken}

Redactie - In dit artikel wordt een beschrijving gegeven van het bedrijf van de Koninklijke Nederlandsche Hoogovens en Staalfabrieken.

$\mathrm{B}$ b V 2

Economische Voorlichting 6 Juni 1941

\section{Vraagstukken der uniforme kostprijsberekening voor gicterijen}

Bezemer. Ir. T. J. - Reeds vroeger zijn vruchteloos pogingen in het werk gesteld om te komen tot een algemeen aanvaard systeem van kostprijsberekening in dezen bedrijfstak. Thans is hier te meer aanleiding voor. Schr. maakt bij zijn behandeling een indeeling naar de verschillende doelstellingen, welke met de uniforme calculatie kunnen worden beoogd. In de eerste plaats is daar de uniforme kostensplitsing in den zin van een uniforme categorische kostensplitsing. Deze kan van belang zijn voor het nagaan van den invloed van prijsstijgingen. Voor een doeltreffende bedrijfsvergelijking is het vorige, gezien het uiteenloopende karakter van de gieterij-bedrijven, niet voldoende, maar moet ook het calculatie-schema uniform zijn. Dit behoeft nog niet te leiden tot volkomen gelijke administratie, maar beoogd wordt het geven van richtlijnen, die de betrouwbaarheid van de kostprijsberekening waarborgen.

$\mathrm{B}$ b $\mathrm{V} 2$

De. Gietcrij Mci 1941

\section{De vraag naar rijwielen}

Dalmulder, dr. J. J. J - Schr, publiceert de berekeningsresultaten betreffende de vraag naar rijwielen, onderscheiden naar fabrieks- en montagerijwielen, alsmede naar prijs- en inkomens-elasticiteit. De negatieve waarde van den beïnvloedingscoëfficiënt van den trend duidt waarschijnlijk op een zekere mate van verzadiging van de vraag.

B b V 8 Maandschtift van het Centraal Burcau voor de Statistick April 1941 
De fabricagekosten bij het in combinatie bedienen van machines of machine-eenheden

$Z$ oethout. Ir. D. - Schr. behandelt het probleem, hoeveel machines men een arbeider het meest rationeel kan laten bedienen. Het eene uiterste is voor iedere machine een arbeider aan te stellen, waardoor leegloop van de machines beslist voorkomen wordt. Het andere uiterste is zooveel machines door een arbeider te laten bedienen dat hij zeker geen moment zonder werk is. Daar tusschen ligt een compromis, waarbij de totale kosten per productieeenheid zoo laag mogelijk zijn. Bij dit vraagstuk moet er rekening mede gehouden worden dat er onderbrekingen van verschillende aard zijn, regelmatige, zooals het verwisselen van spoelen en onregelmatige, zooals draadbreuk. Schr. ontwikkelt de methoden, die gevolgd moeten worden ter berekening van het meest economische aantal te bedienen machines en geeft een aantal karakteristieke en uiteenloopende voorbeelden waarin deze methoden worden toegepast. $\mathrm{B}$ b V 13

De Ingenicur 11 April 1941

De Nederlandsche katoenindustrie

R e da c t i e - In dit artikel wordt een en ander medegedeeld over de geschiedenis van de Nederlandsche katoenindustrie. In de crisisjaren had deze bedrijfstak met groote moeilijkheden te kampen. Herstel volgde door rationalisatie, handelspolitieke maatregelen in Ned. Indië en herziening van het productie-programma. Het artikel geeft cijfers omtrent import en export van grondstoffen en producten.

$\mathrm{B}$ b V 13

Economische Voorlichting 23 Mei 1941

Caseine

Redactie - De gegevens zijn ontleend aan een artikel van Dr. Schubring in het „Bulletin mensuel de statistigue agricole et commerciale" uitgegeven door het Internationaal Landbouw-Instituut te Rome. $Z_{\text {ij }}$ betreffen de productie, internationale handel en prijzen van caseine. Een en ander over de gebruiksmogelijkheden wordt medegedeeld.

B b V $16 \mathrm{~g}$

Economische Voorlichting $30 \mathrm{Mei} 1941$

\section{HANDEI,}

De invloed van prijsregeling en rantsoeneering op den detailhandel

Muiswinkel, dr. F. L. van - De prijsregeling, die noodzakelijkerwijs sterk opportunistisch moet zijn: heeft tal van ongewenschte consequenties, als verlies van belangstelling voor kwaliteit en service, drang naar uitschakeling, onvoldoende invloed van kostprijsverschillen, bedreiging der netto-winstmarge door koppeling van de prijsregeling aan een gedeeltelijken kostprijs.

B b VI 2

Econ. Statistische Berichten 7 Juni 1941

\section{De Europeesche aardappelvoorziening}

Wille ms, J. - Nederland was op het Europeesche continent de grootste aardappelenexporteur, in normale tijden zou Nederland de geheele Europeesche invoerbehoefte ruimschoots kunnen bevredigen. Een aanzienlijke verbruiksbeperking voorziet schr. voor Europa als geheel niet.

B b IV 2

Econ. Statistische Berichten 4 Juni 1941

\section{Eenige opmerkingen over de ontwikkeling der chain-stores in de Vereenigde Staten gedurende de laatste twintig jaren}

L a mbers, H. N. - Schr. bespreekt achtereenvolgens: de wenschelijkheid van groot- of kleinbedrijf in den detailhandel, de functie van den kleinhandel, de bedrijfspolitiek der filiaalonderneming, de invloed van de bedrijfsgrootte daarop, haar prijspolitiek en beschouwt daarna de ontwikkeling van de chain-stores in drie perioden, nl. vóór 1929, van 1929 tot 1935 en na 1935. Verschillende bevorderende en tegenwerkende invloeden worden nog door schr. in het bijzonder bekeken, zooals de kostenstructuur der filiaal-onderneming, de conjunctuur en wetgeving.

B b VI 4

De Economist April en Mei 1941

\section{Exploitatie en rendement van onroerende goederen}

Pas, Dr. W. G. J. t en - In het eerste gedeelte van dit artikel vinden we gegevens over den omvang en de verspreiding van het onroerend goed der Nederlandsche levensverzekerings-maatschappijen. Daarna volgen de gegevens omtrent de exploitatie van dit onroerend goed. Deze worden met behulp van. een aantal verhoudingscijfers overzichtelijk gegroepeerd. Gevolgtrekkingen worden gemaakt t.av. den invloed der conjunctuur en der bedrijfspolitiek op de exploitatie. Afzonderlijk worden gegevens verschaft omtrent de exploitatie van landelijke eigendommen. 


\section{FINANCIERINGSINSTELLINGEN}

\section{Balansstatistieken van Hypotheekbanken}

Het Centraal Bureau voor de Statistiek en het Nederlandsch Economisch Instituut te Rotterdam zijn overeengekomen om het werk van de balansstatistieken, die verscheidene jaren achtereen in "De Kroniek van dr. mr. A. Sternheim" werden gepubliceerd en besproken, voort te zetten. De eerste vrucht van deze samenwerking is deze publicatie van hypotheekbankbalansstatistiek. Het blijkt, dat de normale winstbronnen een behoorlijk overschot boven de kosten laten. Voorts blijkt de concentratie op leeningen van meer dan $f$ 100.000.-, op gebouwde eigendommen en op de grootste steden. Deze concentraties zijn verklaarbaar, maar brengen bijzonder risico mee.

B b X $4 \quad$ Maandschrift van het Centraal Bureau voor de Statistick April 1941

\section{BOEKEN-REPERTORIUM}

\section{A. ACCOUNTANCY}

\section{LEER VAN DE INRICHTING}

Hansen, Palle. Den industrielle Koptoplan. Köbenhavn, 1940.

Kosiol, Erich. Der Jahresabschlusz in Industriebetrieben. Abschlusstechnik für das neuzeitliche Rechnungswesen. Wiesbaden, 1941.

Kottmann, Otto. Betrieblicher Rechnungswesen im Durchschreibeverfahren. Gesamtaufbau einer neuzeitlichen Betriebsbuchhaltung. Stuttgart, 1941.

Lacke, $C$. und $E$. vom Orde. Die Buchführung im Fertigungsbetrieb. Nach den Richtlinien zur Organisation der Buchführung und den Grundsätzen der Kostenrechnung. Leipzig, 1941.

Witte, $I$. $M$. Die monatliche Erfolgsrechnung im Handel. Ein neuzeitliches Kalkulationsverfahren. Berlin, 1941.

\section{B. BEDRIJFSHUISHOUDKUNDE}

\section{a. ALGEMEENE BEDRIJFSHUISHOUDKUNDE}

\section{WAARNEMINGSMIDDELEN}

Witte, 1. M. Die monatliche Erfolgsrechnung im Handel. Ein neuzeitliches Kalkulationsverfahren. Berlin, 1941.

\section{LEER VAN DEN KOSTPRIJS EN DE PRIJSVORMING}

Paris, Gustave. Le prix de revient dans l'industrie. Neuchâtel, 1940.

\section{LEER VAN DE ORGANISATIE}

Ippolito, Teodoro $D^{\prime}$. Principi di ragioneria delle aziende corporative. Puntata I. Milano, 1940.

\section{b. BIJZONDERE BEDRIIVEN}

\section{INDUSTRIE}

Funke, Hermann. Die Betriebswirtschaft im Machinenbau. Halle, 1941.

Gjermoe, Eilif. Den ökonomiske utvikling i fabrikkindustrien 1932-1937. Oslo, 1940. Hansen, Palle. Den industrielle Koptoplan. Köbenhavn, 1940.

Kosiol, Erich. Der Jahresabschlusz in Industriebetrieben. Abschlusstechnik für das neuzeitliche Rechnungswesen. Wiesbaden, 1941.

Lehmann. Leistungssteigerung in der Ziegelindustrie. Berlin, 1941.

Lucke, C. und E. vom Orde. Die Buchführung im Fertigungsbetrieb. Nach den Richtlinien zur Organisation der Buchführung und den Grundsätzen der Kostenrechnung. Leipzig, 1941.

Palomar, Patricio. La industria del cemento en Espana. Barcelona, 1940. 